\title{
Pavel Sergeevich Strelkov (In Honor of His 70th Birthday)
}

PACS numbers: $01.60 .+\mathrm{q}$

DOI: $10.1134 / \mathrm{S} 1063780 \mathrm{X} 09100134$

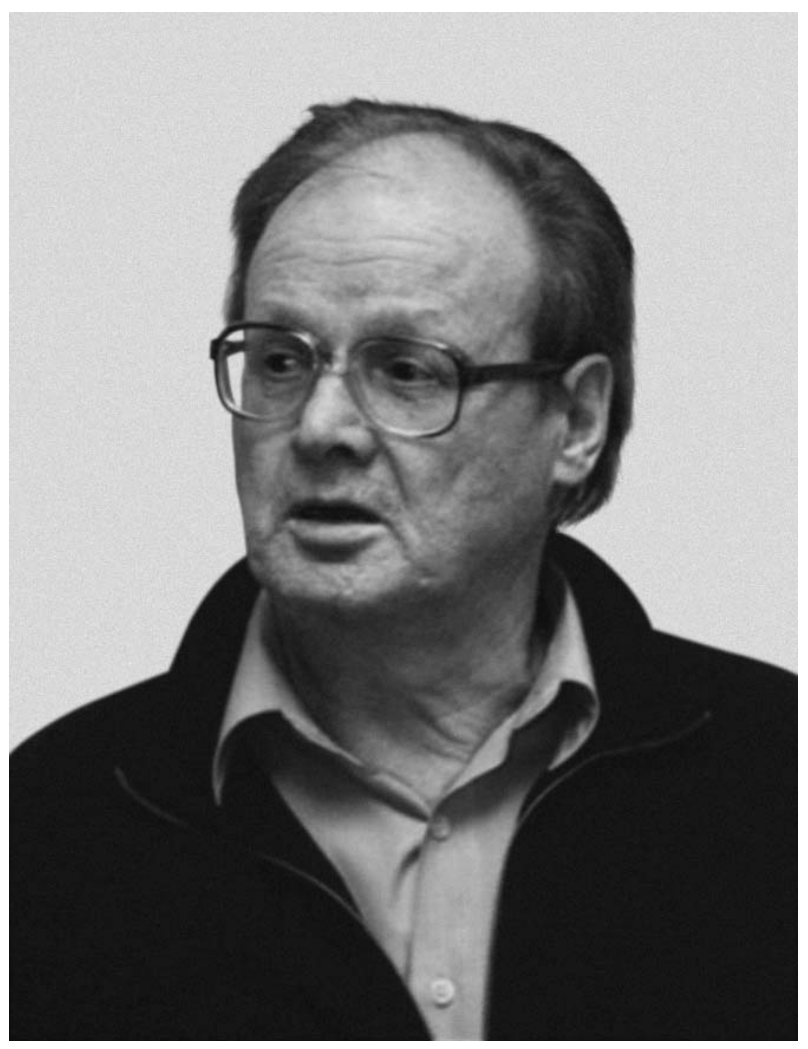

July 20, 2009, was the 70th birthday of Professor Pavel Sergeevich Strelkov, the head of the Laboratory of Plasma Electronics at the Plasma Physics Department of the Prokhorov Institute of General Physics of the Russian Academy of Sciences.

Pavel Strelkov is a second-generation physicisthis father, Sergei Pavlovich Strelkov, was an eminent mechanical physicist, professor in the Physical Faculty of Moscow State University, and one of the founders of the Central Aerohydrodynamic Institute.
Strelkov began his scientific activity in the early 1960 s as a graduate student at the Lebedev Physical Institute. He moved on from being a laboratory assistant and junior scientist to the head of a sector (in 1982) and laboratory (in 1988). The laboratory he headed survived in the harsh 1990s and is continuing to work successfully today, at the height of the crisis. Over the past two decades, Strelkov's team has created a widely tunable plasma relativistic microwave oscillator capable of operating in single-pulse and repetitive modes and a broadband relativistic plasma microwave amplifier.

Strelkov is a highly qualified experimentalist in the fields of plasma physics and microwave electronics. All the results presented in his papers are completely reliable, and Strelkov has dozens of arguments in favor of their validity.

As a laboratory head, Strelkov is easy to contact, but, at the same time, is highly exacting and intolerant toward any carelessness in experiments. This concerns not only his employees, but also to any other physicist with whom he is in contact.

Active scientific work is impossible without relaxation. Besides playing badminton in the summer, Strelkov plays hockey in a team that is partially comprised of his colleagues-professors and graduates from the Physical Faculty of Moscow State University. Strelkov is an affectionate family man, a father of three children, and a fond grandfather.

In his 70th year, Strelkov is full of strength and energy and, more importantly, of ideas and proposals of how to not only survive in these hard times, but also move forward.

We heartily congratulate Pavel Sergeevich on his birthday and wish him robust health, further scientific achievements, and happiness in his family life.

Colleagues, pupils, and friends 